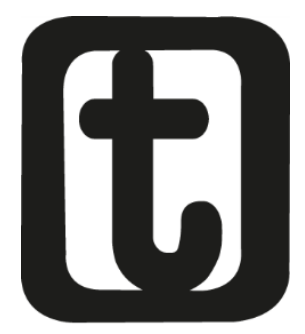

\title{
REESTRUTURAÇÃO PRODUTIVA E HIPERTROFIAÇÃO DA ASSISTÊNCIA SOCIAL: A OFENSIVA DO CAPITAL NO BRASIL
}

Productive restructuration and hyperatrophy of social assistance: an offensive of capital in brazil

\section{Sheyla Suely de Souza Silva ${ }^{1}$ Jordeana Davi² Moema Amélia Serpa Lopes de Souza ${ }^{3}$ Maria Aparecida Nunes dos Santos ${ }^{4}$}

\section{RESUMO}

Este artigo sistematiza estudos sobre os redirecionamentos da proteção social brasileira, cujos resultados evidenciam que, no contexto da atual ofensiva capitalista, há uma estreita relação entre os processos de financeirização, reestruturação produtiva e reestruturação da proteção social. Assim, através da análise das

\footnotetext{
1 Professora da Universidade Estadual da Paraíba (UEPB), Doutoranda em Serviço Social pela UFPE. E-mail: <sheylasuelyss@ig.com.br>

2 Professora Universidade Estadual da Paraíba (UEPB), Doutora em Serviço Social pela UFPE. E-mail: <jordeana@ig.com.br>.

3 Professora Universidade Estadual da Paraíba (UEPB), Doutora em Serviço Social pela UFPE. E-mail: <serpamoema@gmail.com>.

${ }^{4}$ Professora Universidade Estadual da Paraíba (UEPB), Mestre em Serviço Social pela UFPB. E-mail: <cidanunescg@hotmail.com>.
} 
relações entre as particularidades da proteção social na realidade brasileira e as macrodeterminações do processo de restauração capitalista, concluímos que a hipertrofiação da assistência social no Brasil, numa perspectiva de expansão focalizada e seletiva, assentada nos programas de transferência de renda, reflete estratégias de redução dos gastos sociais; de desuniversalização dos direitos sociais e mercantilização das demais políticas da seguridade social e de minimização dos efeitos da reestruturação produtiva sobre a integralidade social, em substituição aos direitos do trabalho e em consonância com os objetivos do capital de liberar-se dos custos da reprodução da força de trabalho e de transferir o fundo público para a esfera financeira.

\section{PALAVRAS-CHAVE}

Capitalismo Contemporâneo. Reestruturação Produtiva. Precarização do Trabalho. Proteção social. Assistência social.

\section{ABSTRACT}

This article systematizes studies about redirections in Brazilian social protection, which results show that in the context of current capitalist offensive, there is a narrow relation between financing processes, productive restructuration and social protection restructuration. Therefore, through the relations analysis between particularities of social protection in Brazilian reality and macro determinations of capitalist restoration process, we conclude that hypertrophy of social assistance in Brazil in a selective and focused perspective expansion, settled in income transfer programs reflects strategies of social costs reduction; desuniversalization of social rights and mercantilization of other social security policies and minimization effects of productive restructuration about social integrality replacing working rights policies and following capital objectives towards liberating costs for working forces reproduction and for transferring public fund to the financial sphere. 


\section{temporolis}

SILVA, S. S. S.; DAVI, J.; SOUZA, M. A. S. L. de.; SANTOS, M. A. N. dos.

REESTRUTURAÇÃO PRODUTIVA

\section{KEYWORDS}

Contemporary Capitalism. Productive Restructuration. Precarious Work. Social Protection. Social Assistance.

\section{INTRODUÇÃO}

Aparentemente, os avanços normativos e institucionais no âmbito da Política de Assistência Social, a partir da Constituição Federal de 1988, da Lei Orgânica de Assistência Social (LOAS) e, em especial, do marco regulatório e da implementação do Sistema Único de Assistência Social (SUAS), apontam para a consolidação desta política, numa perspectiva de integração e fortalecimento da proteção social brasileira. No entanto, enquanto objeto circunscrito na realidade social, a assistência social abriga avanços e contradições que só podem ser analisados à luz de uma leitura crítica que evidencie as mediações e interesses subjacentes às particularidades da proteção social brasileira, em função das atuais macrodeterminações do capital.

O recurso heurístico da totalidade, ao requerer a articulação entre as esferas da política e da economia, permite-nos identificar que a proteção social brasileira se particulariza em função de dois fenômenos próprios da atual fase da restauração capitalista: precarização do trabalho e retração das propostas universalistas de proteção social. Neste contexto, a hipertrofiação da política de assistência social, no Brasil, vem dando suporte à acolhida da reestruturação produtiva, minimizando seus danos e revertendo indicadores de desigualdade; assumindo o papel de integração social que caberia ao trabalho e desuniversalizando os direitos sociais. Para entender as implicações da atual reestruturação produtiva, buscamos destacar os processos de generalização e 
crise do assalariamento, os elementos ideológicos do debate contemporâneo sobre o suposto fim do trabalho e a real ofensiva do capital subjacente a essa reestruturação. A seguir, evidenciamos as inflexões dessa ofensiva sobre a proteção social brasileira.

\section{O CAPITALISMO CONTEMPORÂNEO E SUA OFENSIVA AO TRABALHO}

\subsection{A generalização do assalariamento como pressuposto do lucro}

A sociabilidade capitalista é erigida - num dado momento histórico e pressupondo um determinado nível de desenvolvimento das forças produtivas - a partir do modo como os homens se organizam para produzir e reproduzir seus meios de vida e de produção. Nesse processo, esta sociabilidade capitalista ou modo de produção capitalista engloba os vínculos e relações que intermedeiam a e derivam da ação transformadora da natureza, ou seja, engloba a produção e a reprodução das [suas próprias] relações sociais de produção. Nos termos de Marx (1977 apud IAMAMOTO; CARVALHO, 1993, p. 30), o capital é uma relação social de produção; é a relação de produção da sociedade burguesa.

Enquanto relação social, o capital pressupõe, necessariamente, o trabalho; compondo com ele uma unidade dialética, na qual "[...] um se expressa no outro, um recria o outro, um nega o outro. $\mathrm{O}$ capital pressupõe como parte de si mesmo o trabalho assalariado" (IAMAMOTO; CARVALHO, 1993, p. 31, grifo nosso). Esta unidade de contrários expressa outras contradições que lhe são fundamentais, das quais se destaca, por um lado, uma produção crescentemente coletiva, social; por outro, a apropriação privada dos meios de produção e da riqueza socialmente produzida; colocando em confronto duas classes, também antagônicas entre si e fundamentais ao modo de produção capitalista: de um lado, o 


\section{temporolis}

SILVA, S. S. S.; DAVI, J.; SOUZA, M. A. S. L. de.; SANTOS, M. A. N. dos. REESTRUTURAÇÃO PRODUTIVA

capital (a burguesia), detentor dos meios de produção e de subsistência; de outro, a classe dos trabalhadores (o trabalho) que, expropriados dos meios de produção, para sobreviver, vendem a única propriedade de que dispõem, que é sua força de trabalho, agora transmutada em mercadoria.

A generalização do assalariamento consolidou o modo de produção capitalista e sua modalidade específica de trabalho: o trabalho abstrato. O capitalismo invadiu o campo com a sua lógica e suas relações mercantis, complexificando as relações de troca, cujo objetivo central passou a ser a acumulação de riqueza e a obtenção do lucro. Nesse processo, generalizou-se, também, a separação entre os camponeses e a terra, entre o produtor e os meios de produção e, paralelamente, complexificou-se a divisão social do trabalho.

A partir do desenvolvimento desses processos, o modo de produção capitalista propriamente dito se caracteriza pela penetração do capital na esfera da produção, superando o capital comercial em capital industrial ${ }^{5}$. É o primeiro modo de produção no qual o capital se apropriou [integralmente] dos meios de produção e penetrou na produção propriamente dita. Este monopólio dos meios de produção tornou-se possível no desenvolvimento e complexificação do maquinário, propiciado a partir da primeira revolução industrial, que tornou oneroso e inacessível aos trabalhadores a obtenção de

\footnotetext{
${ }^{5}$ Mandel (1978) esclarece que o capital, enquanto valor que se acresce de uma mais-valia, já prefigurava nas operações econômicas da sociedade da pequena produção mercantil (pré-capitalista), na qualidade de capital comercial. Para compreender essa precedência do capital ao capitalismo, é interessante a leitura da discussão, em Marx (1999), sobre as categorias simples e complexas, que permite-nos entender como o capital, já presente na sociedade pré-capitalista, complexificou-se e generalizou-se na relação social capitalista que, hoje, pressupõe e extrapola o capital como mera operação econômica, atingindo a totalidade social.
} 
unidades fabris, deixando-lhes a única opção de vender a sua força de trabalho, em troca de um salário que lhes garantisse sua sobrevivência e de sua família (MANDEL, 1978).

O motivo pelo qual o trabalho assalariado generalizou-se diz respeito ao fato de que esta transformação do trabalho em mercadoria - a ser mensurada - é pressuposto e requisito necessário para que o capital atinja seu fim: o lucro. Este advém da mais-valia, ou seja, da parte do trabalho não pago ao trabalhador. Mas o que permite ao capitalista comprar trabalho e não pagar integralmente por ele? Eis aí a origem da diferenciação e dissociação entre trabalho (ou trabalho concreto) e trabalho abstrato, bem como a origem da mais-valia e do lucro.

Numa sociedade de subsistência, ou na comunidade primitiva, todos os homens são produtores e todos os homens subsistem daquilo que produzem individual e coletivamente. Neste caso, os homens produzem valores de uso, ou seja, produtos destinados exclusivamente à satisfação das necessidades de reprodução individual e coletiva ${ }^{6}$. No entanto, ao longo da história, ao produzir excedente de produtos, o homem cria a possibilidade de que uma parte da sociedade libere-se da necessidade de trabalhar para o seu sustento. Surge a exploração do homem pelo homem, na qual uma pequena parte da sociedade (os proprietários) se apropria daquilo que a outra parte (os produtores) produz, se apropria, pois, do excedente ou do sobreproduto social. Essa produção (pelo trabalho, pelo produtor) e essa apropriação privada de um excedente (pelo proprietário ou, diríamos, apropriador) possibilitaram a origem das sociedades escravista, feudalista e capitalista, marcadas pelo traço comum da exploração do homem pelo homem.

\footnotetext{
${ }^{6}$ Nas palavras de Marx (1999, p. 57), “[...] o valor de uso só tem valor para o uso, e se efetiva apenas no processo de consumo".
} 


\section{temporolis}

SILVA, S. S. S.; DAVI, J.; SOUZA, M. A. S. L. de.; SANTOS, M. A. N. dos. REESTRUTURAÇÃO PRODUTIVA

A particularidade da produção capitalista reside na generalização progressiva de uma produção destinada prioritariamente à troca. Assim, "[...] a massa dos produtos a serem vendidos deixa de se constituir uma simples produção de valores de uso, para ser produção de mercadorias 7 " (MANDEL, 1978, p. 17) e a troca torna-se a razão de ser da produção, racionalidade e acumulação burguesa ${ }^{8}$. Mas, se o valor de uso de uma mercadoria se expressa no seu consumo, na sua capacidade de satisfazer uma dada necessidade, como se expressa e/ou se mensura o valor de troca desta mesma mercadoria? Que atributo da mercadoria permite sua comparação com as demais mercadorias e equilibra ou padroniza a troca?

7 Essa massificação ou generalização da mercadoria pressupõe outras determinações imanentes ao modo de produção capitalista, decorrentes da complexa e crescente divisão social do trabalho, que separa radicalmente as atividades intelecto-criadoras das atividades mecânicas e destrói a unidade entre produtor, produto e consumo; submetendo o homem à produção, interferindo e submetendo seus ritmos biológicos aos ritmos imperativos da produtividade e fazendo-o sentir/vivenciar o trabalho como uma imposição que lhe é exterior. Eis uma brevíssima síntese do fenômeno da alienação.

8 Observe-se que o capitalismo pressupõe uma inversão de prioridades, atribuindo maior importância ao valor de troca que ao valor de uso. É ilustrativa deste fato a atual crise dos alimentos, deflagrada pela priorização da troca/venda de produtos agrícolas como a soja, a mamona e a cana-de-açúcar para o setor de biocombustíveis, em detrimento da sua troca/venda no setor de alimentos, para a subsistência das populações. Essa opção de mercado se dá em função do maior valor de troca dessas mercadorias no setor de biocombustíveis, desprezando-se o fato de que seu valor de uso no setor de alimentos representa uma questão de sobrevivência humana. Observe-se, também, que, na atual produção destrutiva, os produtos têm menor qualidade de seu valor de uso ou, como referencia Mészáros (2002), há uma taxa decrescente de utilização das mercadorias, para garantir maior rotatividade da sua produção e venda como valor de troca; mais uma vez desprezando-se $o$ aspecto de que essa rotatividade pressupõe a destruição acelerada (e irreversível) da natureza e, com ela, a destruição do homem. 
Para Marx (1999, p. 58), “[...] como encarnação do trabalho social, todas as mercadorias são cristalizações da mesma unidade [...], isto é, do trabalho que se apresenta no valor de troca". Em outras palavras, as mercadorias só se comparam e se referenciam entre si como valor de troca porque apresentam determinados volumes de trabalho. A equivalência entre mercadorias é possível extinguindoIhes as diferenças qualitativas de seus valores de uso e encarnando-lhes volumes iguais do mesmo trabalho. Mas, este "[...] mesmo trabalho [...]" só é possível enquanto uma abstração da racionalidade capitalista, a qual abstrai de cada processo real de trabalho as suas condições concretas de realização, indiferenciando-lhe como trabalho em geral; transformando ou metamorfoseando trabalho concreto em trabalho abstrato. Assim,

[...] o trabalho que põe o valor de troca é, por isso, indiferente diante da forma particular do próprio trabalho [...] como valores de troca [as mercadorias] apresentam trabalho igual, sem diferenças, isto é, trabalho em que a individualidade dos trabalhadores se extinguiu [...]; trabalho abstratamente geral (MARX, 1999, p. 59).

O trabalho pelo qual o capitalista paga o salário é o trabalho abstrato. Trabalho em geral, passível de ser mensurado como unidade de medida de valor (de troca) de todas as mercadorias, dentre elas, a própria mercadoria força de trabalho, expressa como trabalho desumanizado, exteriorizado como coisa vendável, e, "[...] quanto mais a produção de mercadorias se generaliza, tanto mais o trabalho se regulariza, e mais a sociedade se organiza em torno de uma contabilidade fundamentada no trabalho" (MANDEL, 1978, p. 21) ${ }^{9}$. Nesta perspectiva, segundo Rubin (1980, p. 145): “[...]

${ }^{9}$ Essa contabilidade propõe que o valor de troca da mercadoria seja estipulado pela quantidade de trabalho socialmente necessário para produzir e este trabalho socialmente necessário é expresso pelas condições médias de produtividade de 


\section{temporalis}

SILVA, S. S. S.; DAVI, J.; SOUZA, M. A. S. L. de.; SANTOS, M. A. N. dos. REESTRUTURAÇÃO PRODUTIVA

a igualação das várias formas de trabalho e a abstração de suas propriedades concretas é a única relação social que transforma a totalidade de unidades econômicas privadas numa economia social unificada".

A força de trabalho tem seu valor definido pela quantidade de trabalho socialmente necessário para se reproduzir e, tanto menor o tempo de trabalho socialmente necessário para reproduzir a força de trabalho, menor o seu valor. Assim, a mais-valia e o lucro advêm da "[...] diferença entre o valor produzido pela força de trabalho, e as suas próprias despesas de manutenção [...]" e " [...] o equivalente do salário representa sempre APENAS uma fração do dia de trabalho; e o que está para além dessa fração é a mais-valia" (MANDEL, 1978, p. 34-35): trabalho gratuito cedido ao capitalista.

Observamos, então, que a economia capitalista está pautada na exploração do trabalho, tomado contabilisticamente como trabalho abstrato, para que possa produzir um valor que se realiza na troca. Este processo permite ao capitalista apropriar-se, gratuitamente, da maior parte da produção do trabalho, mascarando essa apropriação através do pagamento de salário, o que justificou, historicamente, a generalização do assalariamento, porque necessária à reprodução ampliada do capital na fase industrial (taylorista/fordista).

uma dada sociedade, numa dada época. A relação entre a quantidade de trabalho efetivamente realizado na produção da mercadoria e a quantidade de trabalho socialmente necessário para a produção dessa mesma mercadoria vai delimitar os padrões de lucro/superlucro/prejuízo de cada unidade produtiva/empresa e justificar a concorrência/corrida por maior produtividade entre os mesmos ramos de produção, influindo enormemente nas questões do trabalho e do preço da força de trabalho (salário). Para aprofundar esta discussão, sugerimos a leitura de Mandel (1978) e Rubin (1980), dentre outros.

Temporalis, Brasilia (DF), ano 10, n.20, p.167-196, jul./dez. 2010. 
No entanto, em sua tendência cíclica ${ }^{10}$, o capital se reordena periodicamente, para recompor suas taxas de lucro e acumulação. O atual reordenamento do capital é marcado por uma reestruturação produtiva que - apropriando-se da ciência e da tecnologia como forças produtivas - está pautada na expulsão de amplas massas de trabalhadores do mercado de trabalho, embora não prescinda do trabalho como fundamento da produção da riqueza social e da acumulação capitalista. Mas, como estratégia de maior extração de mais-valia, privilegia, por um lado, a obtenção de trabalho morto, consolidado na mais avançada tecnologia disponível (sistemas de telecomunicações, automação, robótica etc., frutos de séculos de investimentos materiais, financeiros e intelectuais oriundos maciçamente do trabalho), em detrimento do trabalho vivo assalariado; por outro, para livrar-se dos custos de produção, o capital estimula e prolifera formas de subcontratação do trabalho que externalizam os trabalhadores das empresas e retroagem nos avanços e conquistas em torno da composição do Estado protetor. Surgem os fenômenos do desemprego estrutural, da precarização do emprego e da renda e da desproteção social.

\section{REESTRUTURAÇÃO PRODUTIVA E CRISE DO ASSALARIAMENTO: ENTENDENDO SUAS IMPLICAÇÕES E OS ELEMENTOS IDEOLÓGICOS DO DEBATE CONTEMPORÂNEO SOBRE O FIM DO TRABALHO}

Mota e Amaral (1998, p. 31) afirmam que a reestruturação produtiva materializa-se "[...] na criação de novas formas de produção de mercadorias, mediante a racionalização do trabalho vivo, pelo uso da ciência e tecnologia e pela implementação de

\footnotetext{
10 Mandel (1990) dá uma excelente contribuição à compreensão da dinâmica cíclica e tendente a crises do capital, caracterizada por períodos de onda larga expansiva e onda larga recessiva, deflagrados em função da sua capacidade de manutenção/ampliação/recessão das taxas de lucro e acumulação.
} 


\section{temporolis}

SILVA, S. S. S.; DAVI, J.; SOUZA, M. A. S. L. de.; SANTOS, M. A. N. dos. REESTRUTURAÇÃO PRODUTIVA

formas de 'externalização' da produção [...]”, como estratégias que conciliam o aumento da produtividade com a redução dos custos de produção. Assim, automação e flexibilização são as estratégias centrais da reestruturação produtiva no âmbito específico da produção.

Nessas perspectivas, se a consolidação do capitalismo industrial empreendeu um movimento massivo de trânsito dos trabalhadores para as fábricas e generalizou o fenômeno do assalariamento, em sua fase de acumulação flexível, assistimos à inversão deste trânsito, ou seja, uma ampla expulsão dos trabalhadores do mercado de trabalho e uma consequente crise da sociedade salarial $^{11}$ e, com ela, a crise das variadas formas jurídicoinstitucionais de proteção social e trabalhista e de enfrentamento público das expressões da questão social.

Ainda segundo Mota e Amaral (1998, p. 33-34), “[...] a externalização da produção não passa de uma nova forma de estruturação do trabalho abstrato e que se revela como um verdadeiro reino de liberdade, propriedade e igualdade". Nesse "[...] novo reino da produção [...]", o trabalhador crê-se proprietário e livre, já que, por um lado, parece decidir o seu próprio processo de trabalho e, por outro, vive a ilusão de uma sociedade de produtores independentes, sem vendedores de força de trabalho, "[...] posto que o contrato de compra e venda da força de trabalho está se metamorfoseando num contrato de fornecimento de mercadorias" (TEIXEIRA; OLIVEIRA, 1996, p. 73).

\footnotetext{
${ }^{11}$ Para apropriação desta discussão, sugerimos a leitura de autores de diferentes perspectivas teórico-metodológicas, cujas contribuições são indispensáveis, a saber: Castel (1998), Antunes (1995; 1999); Teixeira e Oliveira (1996), dentre outros.
} 
Nesse sentido, Lessa (2002) esclarece que a (a) absorção de atividades de planejamento e controle pelos próprios trabalhadores, (b) a reaproximação das atividades de planejamento com o processo produtivo e (c) a redução da distância entre as atividades que realizam a mais-valia (circulação) e aquelas que a produzem criam as ilusões de que os trabalhadores libertaram-se do controle do capital e de que as esferas de produção e circulação teriam se fundido. Tal fusão busca desqualificar o caráter material do trabalho e difundir uma concepção de trabalho que incorpore (como âmbitos de produção de riqueza) dimensões imateriais, como as atividades de planejamento, organização, comunicação e marketing; "[...] por essa via, a 'reestruturação produtiva' em curso tem servido de 'argumento empírico' para reforçar a indevida identificação teórica entre as categorias de trabalho e trabalho abstrato"12 (LESSA, 2002, p. 30).

Nesse contexto, com tal (aparente) validação empírica e subjetivoideológica, difundem-se as teorias sobre o fim do trabalho, as quais evocam centralidade, hegemonia e qualidade de ser fundante ao trabalho imaterial ${ }^{13}$, desprezando o fato de que tal dimensão da economia, embora hoje hipertrofiada, ainda pressupõe o trabalho material como fundamento da produção de riqueza.

\footnotetext{
12 No plano empírico, constata-se uma hipertrofiação do setor de serviços, articulada a uma retração do setor produtivo, o que, numa primeira e superficial aproximação, respalda as teses do fim da centralidade do trabalho, sob o argumento da inviabilidade de mensuração do trabalho socialmente necessário à produção dos serviços e à reprodução desses trabalhadores.

13 Hardth e Negri (2001) definem o trabalho imaterial prioritariamente como serviço, uma vez que, para tais autores, sua produção não resulta em bens materiais e duráveis. Assim, a produção ou trabalho imaterial envolveria serviços, produção cultural, conhecimento ou comunicação (HARDT; NEGRI, 2001 apud PRADO, 2005).
} 


\section{temporolis}

SILVA, S. S. S.; DAVI, J.; SOUZA, M. A. S. L. de.; SANTOS, M. A. N. dos. REESTRUTURAÇÃO PRODUTIVA

Pressupondo uma esfera autônoma de soberania individual que "[...] não é fundada sobre simples desejos de consumo nem apenas atividades de divertimento e recreação [...]", mas “[...] por atividades sem fim econômico [...]", com finalidade de “[...] criação de valores de uso (objetos ou serviços mútuos) sem valor mercantil e cuja produção mercantil seria impossível por não ter rentabilidade", Gorz (1987, p. 100-101) afirma:

[...] a inversão da ordem de prioridades, com a subordinação do trabalho social com finalidade econômica à expansão das atividades da esfera de autonomia individual está acontecendo em todas as classes das sociedades superdesenvolvidas, particularmente entre o neoproletariado pósindustrial: a verdadeira 'vida' começa fora do trabalho, o trabalho torna-se um meio de ampliar a esfera do não trabalho, é a ocupação temporária pela qual os indivíduos adquirem a possibilidade de dar continuidade às suas atividades principais. Trata-se de uma mutação cultural que delineia a passagem para a sociedade pós-industrial.

O referido autor sentencia, então, que "[...] a inversão dessa relação de subordinação marcará o fim da economia política e o advento do 'socialismo pós-industrial', ou seja, do comunismo".

Também para Lazzarato e Negri (2001, p. 26), o “[...] ciclo do trabalho imaterial é pré-constituído por uma força de trabalho social e autônoma, capaz de organizar o próprio trabalho e as próprias relações com a empresa". Tal trabalho imaterial tende a tornar-se hegemônico e ruirá a teoria do valor proposta por Marx (1983), uma vez que o trabalho em forma imediata deixou de ser a fonte de riqueza e o tempo de trabalho deixou de ser a medida da riqueza e, "[...] o valor de troca deve cessar de ser a medida do valor de uso" (LAZZARATO; NEGRI, 2001, p. 29), pondo em crise o próprio capitalismo, o qual, hoje, mantém um domínio e controle 
meramente formal e externo sobre um processo produtivo cujo conteúdo "[...] pertence sempre mais a outro modo de produção, à cooperação social do trabalho imaterial” (LAZZARATO; NEGRI, 2001. p. 31).

Contrapondo-se às teses supracitadas, Prado (2005) adverte que a própria igualação operada pelos autores ${ }^{14}$ entre trabalho imaterial e serviços coloca um problema de base em suas teorias, uma vez que há serviços que são produtos materiais do trabalho (como um corte de cabelo, por exemplo) e há bens que são produtos imateriais do trabalho (como, por exemplo, um programa de computador). Em um segundo equívoco, tais autores reduzem o trabalho abstrato ao seu aspecto fisiológico ${ }^{15}$, o que lhes permite sugerir que o valor não pode mais ser pensado como medida. Tal crítica só parece precedente porque, segundo Prado (2005), os autores desprezam as diferenças histórico-conceituais entre trabalho concreto e trabalho abstrato, tomando este último como expressão exclusiva do e idêntica a trabalho.

Na derivação desses equívocos, Hardt e Negri (2001 apud PRADO, 2005) tomam a predominância dos serviços - entendida como trabalho imaterial - como espaço complexo e qualificado de cooperação mútua, autônomo e alternativo ao capitalismo. Em seus novos territórios produtivos, os trabalhadores teriam

\footnotetext{
14 A crítica de Prado (2005) refere-se mais especificamente a Hardt e Negri (2001), mas, a nosso ver, pode ser estendida aos demais autores que, aqui trabalhados, propõem a centralidade do trabalho imaterial.

15 Embora pressuponha o aspecto fisiológico do dispêndio de energia física, o trabalho abstrato não se reduz a tal aspecto, nem se iguala unicamente através dele, pois se constitui uma categoria social que extrapola seu aspecto material. Assim, se tomado exclusivamente pela perspectiva fisiológica, o trabalho abstrato não produz, necessariamente, valor; pois só o faz enquanto fenômeno/relação social complexa. Para aprofundar a discussão, sugerimos a leitura de Rubin (1980).
} 


\section{temporalis}

SILVA, S. S. S.; DAVI, J.; SOUZA, M. A. S. L. de.; SANTOS, M. A. N. dos. REESTRUTURAÇÃO PRODUTIVA

superado a alienação capitalista por serem gestores autônomos de seus processos produtivos e proprietários de suas máquinas, insumos, produtos finais, ainda que estes produtos destinem-se às demandas de mercado da produção capitalista propriamente dita.

Lessa (2005) alerta que as teses da imaterialidade do trabalho são mais que a interpretação das novas formas de produção e gerência, pois incluem uma concepção política que propõe uma possível compatibilidade entre comunismo, mercado, propriedade privada, dinheiro e Estado; um comunismo "[...] sem a superação das classes sociais e com a manutenção do controle da produção nas mãos dos burgueses" (LESSA, 2005, p. 38). O autor esclarece, elucidativamente, que, nesses novos arranjos produtivos, 0 trabalhador doméstico - externalizado da fábrica - é tão explorado que, "[...] para poder trabalhar, deve fornecer parte do capital constante [...] dos custos administrativos [ele é seu próprio capataz] e abrir mão de toda proteção social" (LESSA, 2005, p. 42-43).

A apropriação desse debate nos permite perceber os reais interesses do capital numa reestruturação produtiva pautada na superexploração. Além dessa reestruturação e do discurso sobre o fim do trabalho, a ofensiva do capital articula outras estratégias que também visam à passivização do trabalho e inflexionam o padrão de proteção social brasileira.

\section{A OFENSIVA DO CAPITAL AO TRABALHO E SUAS INFLEXÕES SOBRE A PROTEÇÃO SOCIAL BRASILEIRA: A HIPERTROFIAÇÃO DA POLÍTICA DE ASSISTÊNCIA SOCIAL}

Com vistas à superação de sua atual crise estrutural ${ }^{16}$, o capital articula à reestruturação produtiva um processo de globalização

\footnotetext{
${ }^{16}$ Para além de seu caráter cíclico, tendente a crises periódicas, configuradas por períodos de ondas largas recessivas (MANDEL, 1990), alguns autores alertam
}

Temporalis, Brasilia (DF), ano 10, n.20, p.167-196, jul./dez. 2010. 
que, para Chesnais (2008) $)^{17}$, corresponde à criação de um espaço livre de restrições às operações de produção e de realização de mais-valia pelo capital, que lhe permita uma alta concentração de lucros, à escala internacional.

Os principais elementos desse processo são: a liberalização das finanças, do comércio e dos investimentos; a recorrência à criação de capital fictício e a re-incorporação da União Soviética e da China como elementos do sistema capitalista mundial, execrando quaisquer resquícios de modelos de sociedade alternativos ao capitalismo e submetendo todo o globo à lógica, aos interesses e às imposições discricionárias do capital, em sua nova fase imperialista.

Dentre essas imposições, encontram-se os processos de reforma dos Estados nacionais, com vistas à desregulamentação da economia e dos direitos sociais e trabalhistas e à deterioração dos sistemas públicos de proteção social, visando à minimização dos custos de reprodução do trabalho; à apropriação do fundo público em função dos interesses privados do capital e à desmobilização da "[...] resistência dos trabalhadores para a acentuação da taxa de exploração, em defesa da apropriação crescente de mais-valia" (PANIAGO, 2007, p. 4).

Assim, se durante os trinta anos gloriosos, o Estado de Bem-Estar Social conciliou a regulação dos mercados com a intervenção social, sustentando o pacto fordista-keynesiano, no atual contexto

para o caráter estrutural da crise atual, diante da qual o capital não encontra saídas que não se convertam no exponenciamento de suas próprias contradições e consequências desastrosas. Ver, por exemplo, Mészáros (2002), Harvey (2004) e Chesnais (1996; 2008).

${ }^{17}$ Ressaltamos que, ao referir-se a este processo, o autor opta pelo conceito de mundialização. 


\section{temporalis}

SILVA, S. S. S.; DAVI, J.; SOUZA, M. A. S. L. de.; SANTOS, M. A. N. dos. REESTRUTURAÇÃO PRODUTIVA

da acumulação flexível, o capital recapitula sua face democrática e propõe a reatualização dos princípios liberais, iniciando sua ofensiva neoliberal, que se expressa num ataque frontal ao Estado interventor, propondo a sua minimização para os custos sociais, em favor da transferência de recursos para o capital financeiro especulativo. Eis, pois, os elementos articulados e indissociáveis da atual ofensiva do capital: globalização, reestruturação produtiva e reforma do Estado.

O Brasil tem uma inserção subordinada no processo de globalização, tendo em vista sua subserviência às agências internacionais de crédito; sua frágil produção tecnológica e o histórico compromisso de suas elites e do Estado com os interesses do capital internacional. Quanto à reestruturação produtiva, esta vem sendo expressa na terceirização, na informalização e no empreendedorismo, convertendo-se, também, numa individualização de demandas, reforçada em virtude dos apelos ao individualismo e à alta competitividade entre os trabalhadores, quebrando os laços de solidariedade historicamente construídos e inviabilizando a defesa de projetos societários alternativos ao capital (SILVA, 2000; 2009).

Através de um estudo do Centro de Estudos Sindicais e de Economia do Trabalho (CESIT), no setor terciário, em São Paulo, Krein e Gonçalves (2005) ${ }^{18}$ confirmam que as novas mudanças no âmbito da produção vêm fragilizando a capacidade organizativa dos trabalhadores e retroagindo suas conquistas sociais e trabalhistas. Assim, “[...] o resultado desse processo de mudança acentua a diferenciação entre os trabalhadores e pulveriza as

\footnotetext{
18 Realizada entre 2003 e 2005, a pesquisa analisa os impactos das mudanças tecnológicas do setor terciário sobre as relações de trabalho no Brasil, na década de 1990.
} 
organizações de representação coletiva" (KREIN; GONÇALVES, 2005, p. 3).

As mudanças organizativas e tecnológicas da reestruturação produtiva (a) racionalizam custos e aumentam a produtividade do trabalho, (b) reduzem a eficácia da greve e das mobilizações, (c) aumentam o ritmo do trabalho e o comprometimento do tempo social (ou tempo do não-trabalho) e exacerbam a alienação entre o trabalho e o produto do trabalho e, mais gravemente, (d) exacerbam a coerção sobre o trabalho, ao inserir no processo produtivo, como condição de sobrevivência/permanência no emprego, a concorrência entre os trabalhadores, estimulando ações individualistas.

O grande substrato dessas mudanças foi que as empresas obtiveram maior liberdade na determinação das condições de uso e de remuneração do trabalho.

Dando suporte à inserção subordinada do Brasil no processo de globalização e à acolhida de uma reestruturação produtiva pautada na expulsão e na precarização da inserção do trabalhador no mercado de trabalho, encontramos a contrarreforma ${ }^{19}$ do Estado brasileiro, a qual denuncia a fragilidade e a brevidade da reforma democrática proposta na Constituição Federal de 1988 que, em sua essência, contrapõe-se "[...] ao projeto que grassou a hegemonia política e econômica protagonizada pelo neoliberalismo: o ideário do 'livre agir dos mercados', [...] das privatizações e restrições à prestação dos serviços públicos" (ANFIP, 2009, p. 9).

\footnotetext{
${ }^{19}$ Devido ao caráter conservador e regressista dos movimentos do Estado e da Burguesia brasileira, com vistas à manutenção de suas históricas relações de poder e opondo-se às reformas democráticas propostas na década de 1980, Behring (2003) os classifica como movimentos de contrarreforma.
} 


\section{temporalis}

SILVA, S. S. S.; DAVI, J.; SOUZA, M. A. S. L. de.; SANTOS, M. A. N. dos. REESTRUTURAÇÃO PRODUTIVA

A seguridade social brasileira foi instituída a partir da Constituição Federal de 1988 e composta pelas políticas de saúde, previdência e assistência social. No contexto da contrarreforma do Estado, a partir dos anos de 1990, vimos observando um sucateamento das políticas públicas de saúde e de previdência social, privilegiando a sua oferta mercantil, através dos planos e fundos privados, e, paralelamente, no governo Lula, uma hipertrofiação da política de assistência social, assentada nos programas de transferência de renda. Para Boschetti (2009) ${ }^{20}$, os programas de transferência de renda são respostas àqueles que não têm acesso ao trabalho, visando garantir-lhes renda e mantê-los no mercado de consumo para, assim, assegurar a ampliação do capital, o que não se converte em socialização da riqueza.

De fato, observamos que - no contexto da atual reestruturação produtiva, marcada pela superexploração do trabalho, pelo desemprego estrutural e pela precarização do emprego e da renda - a hipertrofiação da assistência social brasileira, assentada nos programas de transferência de renda, cumpre papéis que outrora eram delegados à esfera do trabalho, no que diz respeito à capacidade de consumo das massas populares; à redução dos índices de pobreza e de desigualdades e à integração social.

Segundo dados da PNAD/IBGE (apud ANFIP, 2009), entre 2004 e 2008, a economia brasileira cresceu 26,8\%, superando o desempenho das economias avançadas e reduziram-se as desigualdades sociais e os níveis de pobreza e de indigência em 60\% e 65\%, respectivamente. Para a Associação Nacional dos Auditores Fiscais da Receita Federal do Brasil (ANFIP, 2009), essa redução foi fruto, prioritariamente, da diversificação dos gastos sociais e da ampliação e universalização de programas de transferência de

\footnotetext{
${ }^{20}$ Fala da autora durante o Fórum Social Mundial, ocorrido em Belém (PA), de 27 de janeiro a $1^{\circ}$ de fevereiro de 2009.
}

Temporalis, Brasilia (DF), ano 10, n.20, p.167-196, jul./dez. 2010. 
renda, como o Bolsa Família, além da maior formalização do mercado de trabalho e do aumento real do salário mínimo.

A ANFIP (2009) destaca que a execução orçamentária do conjunto de ações que integram a seguridade social aumentou 98,3\%, enquanto que, dentro deste montante, os dispêndios com benefícios assistenciais e outras ações distributivas da assistência social, como o Bolsa Família, agricultura familiar e segurança alimentar, cresceram $\mathbf{2 1 6 \%}$.

No que diz respeito especificamente ao consumo, somente o Programa Bolsa Família complementa hoje a renda de mais de doze milhões de famílias brasileiras (ANFIP, 2011) e, segundo a ANFIP (2009), o consumo das famílias foi o fator que mais contribuiu para o aumento do PIB. Em 2008, por exemplo, 65\% do aumento da produção nacional - que naquele ano cresceu 5,1\% - deveu-se à ampliação do consumo final das famílias, cuja renda cresceu também devido ao aumento das transferências de renda aos segmentos de menor poder aquisitivo. Nas palavras do então presidente Lula, “[...] essa gente aprendeu a entrar em shopping [...] aprendeu a entrar no supermercado e a comprar as coisas que todo mundo tem direito de comprar" (ROCKMAN, 2009, p. 45).

No entanto, Stédile (2010, p. 65) adverte que “[...] o povão compra tudo à prestação, iludindo-se com um poder de compra sem renda suficiente e paga duas vezes. Uma para a loja e outra para o sistema financeiro, com as maiores taxas de juro do mundo".

Enquanto isso, há elementos que controvertem os saldos positivos do trabalho e da renda tão alardeados pela mídia e pelos órgãos oficiais, neste mesmo período, e que conduzem ao questionamento sobre a responsabilidade do crescimento do 


\section{temporolis}

SILVA, S. S. S.; DAVI, J.; SOUZA, M. A. S. L. de.; SANTOS, M. A. N. dos. REESTRUTURAÇÃO PRODUTIVA

emprego ou da economia na reversão dos indicadores de pobreza e de desigualdade.

Cruzando dados de admissões e demissões no ano de 2008, a ANFIP (2009) observa que houve um alto índice de rotatividade e que o saldo positivo representou menos de $13 \%$ do total de trabalhadores contratados. No que diz respeito à renda, este saldo positivo concentrou-se quase que absolutamente $(82,2 \%)$ em faixas de rendimento de até dois salários mínimos e o IPEA (2008) reconhece que a participação dos trabalhadores na economia nacional em 2008 (41,7\%) sequer recuperou o índice da década de 1990 (45,5\%), o que poderia ser alcançado em 2011, caso o ritmo de crescimento da economia se mantivesse em $4 \%$. No entanto, após os efeitos do crash/2008, em agosto de 2009, o Banco Central anunciou que a expectativa de contração da economia naquele ano havia caído de $0,35 \%$ para $0,34 \%^{21}$; e a previsão de crescimento em 2010 teria aumentado de 3,60\% para 3,80\%, comprometendo as expectativas de crescimento do emprego e da renda.

Ainda em janeiro de 2009, mais de 2.700 trabalhadores da MWM Motores e outros trabalhadores das fábricas de autopeças SABÓ e AMOT, todas em São Paulo, negociaram a redução de jornada e salários para manterem-se no emprego (METALÚRGICOS..., 2009). Em março, o IBGE (2009) divulgou um crescimento da subocupação superior a 14\% (SOARES, 2009) e o Dieese/Seade anunciaram o crescimento da taxa média de desemprego para 15\% nas seis maiores regiões metropolitanas do país (DESEMPREGO..., 2009). Em janeiro de 2010, a Pesquisa de Emprego e Desemprego (PED) do Dieese divulgou a estabilidade da taxa de desemprego

\footnotetext{
${ }^{21}$ Segundo o IBGE (2010), a desaceleração da economia registrou uma variação do PIB nacional, em 2009, na ordem de $-0,2 \%$, considerado economicamente nulo, mas, ainda assim, um dos melhores resultados no cenário mundial, frente aos reflexos do crash de setembro de 2008.
} 
total nessas regiões, no acumulado do ano, passando de 14,1\% para $14,2 \%$, devido a uma perda de 45 mil empregos. Estes dados corroboram o prognóstico de estagnação do quadro de desemprego no Brasil (SEADE;DIEESE, 2010).

Além das negociações de perda de direitos e de rendimentos como subterfúgio para manutenção dos postos de trabalho e do quadro de subocupação dos trabalhadores, a formalização do emprego envolveu a oferta de "[...] benefícios tributários e diminuições de encargos administrativos, além de facilidades creditárias que tornaram viável, conveniente e oportuna a legalização" (ANFIP, 2009, p. 47). Estes incentivos públicos socializaram com os próprios trabalhadores os custos da oferta do emprego. Por outro lado, também são prioritariamente as contribuições sociais sobre os rendimentos dos trabalhadores que compõem o orçamento da seguridade social e assim, mais uma vez, são esses que financiam maciçamente a proteção social e os programas de transferência de renda, evidenciando o caráter regressivo e distributivo da (des)proteção social brasileira ${ }^{22}$.

Enfim, um cálculo simples evidencia o papel que a assistência social vem assumindo no contexto da precarização do trabalho e da renda. Se considerássemos que todo o saldo positivo do emprego

\footnotetext{
${ }^{22}$ Apenas para ilustrar este fato, segundo a Anfip (2009), em 2008, as receitas da Contribuição para o Financiamento da Seguridade Social (COFINS), tributo indireto incidente sobre o faturamento das empresas, arrecadou $\mathrm{R} \$ 119,3$ bilhões, enquanto o tributo direto da Contribuição Social sobre o Lucro das Pessoas Jurídicas (CSLL) arrecadou apenas $\mathrm{R} \$ 42,4$ bilhões, demonstrando que a composição deste orçamento privilegia a tributação dos mais pobres, que são os próprios trabalhadores. Logo, são esses que, em última análise, financiam não apenas as políticas de seguridade social como o superávit primário destinado ao pagamento da dívida pública, uma vez que $20 \%$ dos recursos orçamentários da seguridade social são desviados para tal fim, através do mecanismo da Desvinculação das Receitas da União (DRU).
} 


\section{temporalis}

SILVA, S. S. S.; DAVI, J.; SOUZA, M. A. S. L. de.; SANTOS, M. A. N. dos. REESTRUTURAÇÃO PRODUTIVA

em 2008 (1,4 milhão) houvesse se inserido na faixa salarial equivalente a exatamente dois salários mínimos (lembremos que $82,2 \%$ inseriram-se em faixas salariais de até dois salários mínimos) e que tais postos se mantiveram estáveis nos doze meses do ano (quando o quadro do emprego foi marcado pela rotatividade e apenas os últimos meses do ano registram maiores absorções), o montante total de recursos dos salários obtidos por esses trabalhadores seria em torno de R\$ 15,49 bilhões $^{23}$.

Agora, contrapondo-se esse valor ao montante de recursos destinados apenas aos benefícios de transferência de renda (Programa Bolsa Família), também em 2008, que foi superior a 10,6 bilhões (ANFIP, 2009), elucidamos inequivocamente que tais programas de transferência de renda têm um impacto significativo no aumento do consumo, da produção e do PIB e na reversão dos indicadores sociais, pois, se considerarmos o montante total do saldo positivo do trabalho ${ }^{24}$, juntamente com a transferência de renda, o montante dos programas de transferência de renda equivale a, no mínimo, $40 \%$ do total de rendimentos decorrentes das duas dinâmicas (26,09 bilhões).

Logo, embora não altere material ou substantivamente a situação de pobreza de seus beneficiários, o pequeno acréscimo de renda desses programas assegura às famílias algum poder de consumo, beneficiando a ampliação do capital, ao tempo em que altera a pobreza e a desigualdade social em nível das estatísticas oficiais. Assim, finalizamos com a contribuição de Mota (2010, p. 26), quando destaca que:

\footnotetext{
${ }^{23}$ Cálculos próprios, com base nos dados disponíveis em Anfip (2009) e no Site do Dieese.

${ }^{24}$ Lembramos: hipotético e superestimado, pois muitos trabalhadores inseriramse em rendimentos inferiores a dois salários mínimos e/ou mantiveram-se no emprego por tempo inferior aos doze meses do ano de 2008.
} 


\begin{abstract}
[...] a expansão dos programas é um meio legítimo e legal para enfrentamento da pobreza, mas não se confunde com a redução e superação da desigualdade, posto que nossa concepção de desigualdade é vinculada à questão da acumulação de riqueza e concomitantemente pauperização dos trabalhadores. Portanto, não se restringe ao campo da circulação e dos indicadores de consumo como pensa o Banco Mundial.
\end{abstract}

\title{
5 A GUISA DE UMA CONSIDERAÇÃO MAIS GERAL
}

As atuais transformações no mundo do trabalho são imperativos insuprimíveis do capital em seu atual estágio de restauração que geram consequências como o desemprego em massa, em especial entre os jovens, a ausência ou escassez de renda necessária à subsistência dos trabalhadores (empregados ou não) e suas famílias e, em decorrência, a pobreza e a indigência, as quais ameaçam a ordem e a coesão sociais do próprio modelo capitalista. Nesse sentido, concordamos com Paiva (2006) quando adverte que a subordinação e a inferioridade competitivas do Brasil frente ao mercado externo são compensadas pela superexploração do trabalho, empobrecimento dos trabalhadores e acirramento das desigualdades sociais, colocando para a política de assistência social o desafio de "[...] responder de maneira decisiva, em escala de massas, às necessidades sociais da população brasileira" (PAIVA, 2006, p. 13).

Essa demanda massiva à assistência social confronta-se com o histórico papel desta política de intervir junto àqueles indivíduos considerados inaptos para o trabalho, ampliando sua intervenção para os aptos excluídos desse mercado ou nele precarizados, o que poderia explicar parcialmente sua expansão. No entanto, a compreensão da hipertrofiação da assistência social somente é 


\section{temporalis}

SILVA, S. S. S.; DAVI, J.; SOUZA, M. A. S. L. de.; SANTOS, M. A. N. dos. REESTRUTURAÇÃO PRODUTIVA

possível ao considerarmos que suas macrodeterminações se dão no bojo da tríade neoliberal da globalização, reestruturação produtiva e reforma dos Estados.

Nesse contexto, a ampliação da assistência social brasileira se dá na conjunção de dois elementos próprios, articulados e insuprimíveis da atual fase da restauração capitalista: ampla precarização do trabalho e da renda, com expulsão/externalização de trabalhadores - inclusive aptos e qualificados - do mercado formal de trabalho e retração das propostas e ações universalistas de proteção social.

Destarte, a partir do cotejo entre a particularidade da proteção social na realidade brasileira e essas macrodeterminações do capital, nossa análise revela que, no Brasil, a política de assistência social vem dando suporte à reestruturação produtiva, dissimulando seus danos e indicadores no tocante à extrema pobreza e às desigualdades e assumindo o papel de integração social que caberia ao trabalho. Ao mesmo tempo, sua hipertrofiação, assentada nos programas de transferência de renda, expressa uma estratégia de desuniversalização dos direitos sociais, mantendo o enfrentamento das expressões da questão social pela via distributiva e onerando e responsabilizando maciçamente os trabalhadores, em consonância com a perspectiva da atual ofensiva do capital de liberar-se dos custos de reprodução da força de trabalho e de disponibilizar os recursos públicos para a esfera do capital financeiro.

Observamos que há um alinhamento entre os programas de transferência de renda da assistência social brasileira e os objetivos de fortalecimento do setor econômico, num contexto em que se reatualiza o discurso em favor da regulação estatal, contudo, sempre em prol dos interesses do capital de desenvolver uma nova 
superexploração do trabalho, expressa numa reestruturação produtiva que, externalizando os trabalhadores do espaço da fábrica/empresa e hiperdimensionando o setor informal, se converta em mais-valia - absoluta e relativa - e, assim, garanta a restauração do sistema capitalista em crise.

Nesse sentido, frente à precarização do trabalho e da renda promovida pela atual reestruturação produtiva, a hipertrofiação da assistência social brasileira, assentada na transferência de renda, garante uma integração social das famílias beneficiárias pela via do acesso ao consumo (que, como vimos, beneficia o capital também pela via do financiamento extorsivo da compra em padrões de altíssimas taxas de juro) e reverte as estatísticas oficiais da pobreza e das desigualdades sociais.

Por fim, entendemos que a assistência social brasileira, ao focalizar-se nas famílias em situação de extrema pobreza como critério de transferência de renda, desloca-se de uma referência teórico-metodológica estrutural das desigualdades sociais e, assim, obsta qualquer proposta de enfrentamento da questão social numa perspectiva universalista.

\section{REFERÊNCIAS}

ANFIP. Análise da seguridade social em 2008. Brasília: ANFIP, 2009.

ANFIP. Análise da seguridade social em 2010. Brasília: ANFIP, 2011.

ANTUNES, R. Adeus ao trabalho? São Paulo: Cortez, 1995.

ANTUNES, R. Os sentidos do trabalho. São Paulo: Boitempo, 1999. 


\section{temporolis}

SILVA, S. S. S.; DAVI, J.; SOUZA, M. A. S. L. de.; SANTOS, M. A. N. dos. REESTRUTURAÇÃO PRODUTIVA

BEHRING, E. R. Brasil em contra reforma: desestruturação do Estado e perda de direitos. São Paulo: Cortez, 2003.

CASTEL, R. As metamorfoses da questão social: uma crônica do salário. Rio de Janeiro: Vozes, 1998.

CHESNAIS, F. A mundialização do capital. São Paulo: Xamã, 1996.

CHESNAIS, F. O capitalismo tentou romper seus limites históricos e criou um novo 1929 ou pior. 25 out. 2008. Disponível em: <http://www.educacionista.org.br/jornal/index.php?option=com_c ontent\&task=view\&id=597\&ltemid=3 >. Acesso em: 29 out. 2008.

DESEMPREGO sobe para 15\% em julho em seis áreas metropolitanas do país. Disponível em: Valor online, São Paulo, 28 ago. 2009. < http://www.valoronline.com.br/online/indicadores/10/281456/dese mprego-sobe-para-15-em-julho-em-6-areas-metropolitanas-do-pais >. Acesso em: 18 ago. 2009.

GORZ, A. Adeus ao proletariado: para além do socialismo. Rio de Janeiro: Forense-Universitária, 1987.

HARVEY, D. O novo imperialismo. São Paulo: Edições Loyola, 2004.

IAMAMOTO, M. V.; CARVALHO, R. de. Relações sociais e serviço social no Brasil: esboço de uma interpretação históricometodológica. 9. ed. São Paulo: Cortez, 1993.

IBGE. Em 2009, PIB varia -0,2\% e fica em R\$ 3.143 bilhões. 11 mar. 2010. Disponível em: <http://www.ibge.gov.br/home/presidencia/noticias/noticia_visualiza.php?id_noticia=1571\&id_pagin a=1\&titulo=Em-2009,-PIB-varia--0,2\%-e-fica-em-R\$-3.143-bilhoes $>$. Acesso em: 3 mar. 2010. 
IPEA. Desigualdades sociais são hoje maiores do que em 1990. 12 nov. 2008. Disponível em: <www.ipea.gov.br>. Acesso em: nov. 2008.

KREIN, J. D.; GONÇALVES, J. R. O impacto das mudanças tecnológicas do setor terciário sobre as relações de trabalho no Brasil, na década de 90. In: ENCONTRO NACIONAL DA ANPOCS, 29., 2005, Caxambu. Anais... Caxambu: ANPOCS, 2005.

LAZZARATO, M.; NEGRI, A. Trabalho imaterial: formas de vida e produção da subjetividade. Rio de Janeiro: DP\&A, 2001.

LESSA, S. Mundo dos homens: trabalho e ser social. São Paulo: Boitempo, 2002.

LESSA, S. Para além de Marx? Crítica da teoria do trabalho imaterial. São Paulo: Xamã, 2005. (Coleção Labirintos do Trabalho).

MANDEL, E. A crise do capitalismo. Campinas: UNICAMP/Ensaio, 1990.

. Iniciação à teoria econômica marxista. Lisboa: Antídoto, 1978.

MARX, K. O capital: livro 1, tomo 1. São Paulo: Abril Cultural, 1983.

. Para a crítica da economia política do capital: o rendimento e suas fontes. São Paulo: Nova Cultural, 1999.

MÉSZÁROS, I. Para além do Capital: rumo a uma teoria de transição. São Paulo: Boitempo, 2002.

METALÚRGICOS da MWM e da Sabó aprovam corte na jornada e no salário. Diário do Grande ABC, 29 jan. 2009. Disponível em: 


\section{temporalis}

SILVA, S. S. S.; DAVI, J.; SOUZA, M. A. S. L. de.; SANTOS, M. A. N. dos.

REESTRUTURAÇÃO PRODUTIVA

<http://www.dgabc.com.br/News/5725097/metalurgicos-da-mwme-da-sabo-aprovam-corte-na-jornada-e-no-salario.aspx>. Acesso em: 29 mar. 2009.

MOTA, A. E. Redução da pobreza e aumento da desigualdade: um desafio teórico-prático ao Serviço Social. In: MOTA. A. E. (Org.) As ideologias da contrarreforma e o Serviço Social. Recife: Ed. Universitária da UFPE, 2010.

MOTA. A. E.; AMARAL, A. S. do. Reestruturação do capital, fragmentação do trabalho e serviço social. In: MOTA. A. E. (org.). A nova fábrica de consensos. São Paulo: Cortez, 1998.

PAIVA, B. A. O SUAS e os direitos socioassistenciais: a universalização da seguridade social em debate. Revista Serviço Social e Sociedade, São Paulo, ano 26, n. 87, (especial), 2006.

PANIAGO, M. C. S. Crise estrutural do capitalismo e tendências de desenvolvimento da esfera pública. In: JORNADA INTERNACIONAL DE POLÍTICAS PÚBLICAS, 3., 2007, São Luis. Anais... São Luis: UFMA, 2007. 1 CD-ROM.

PRADO, E. Desmedida do valor: crítica da pós-grande indústria. São Paulo: Xamã, 2005. (Coleção Labirintos do Trabalho).

ROCKMAN, R. E o presente chegou: na tradicional festa de Carta Capital, o otimismo substitui os temores do ano passado, só combatidos então por Lula, que prometia 'marolinha'. Revista Carta Capital, n. 569, out. 2010.

SEADE; DIEESE. Pesquisa de emprego e desemprego: região metropolitana de São Paulo. São Paulo, jan. 2010. Divulgação n.302. 
Disponível em: <http://www.dieese.org.br/ped/sp/pedrmspo110.pdf $>$. Acesso em: 5 mar. 2010.

RUBIN, I. I. A teoria marxista do valor. São Paulo: Brasiliense, 1980.

SILVA, S. S. S. A esfera pública: a ofensiva neoliberal e a questão social no Brasil. Revista Pesquisa em Debate, Recife, 2000.

SILVA, S. S. S. A política social brasileira na conjuntura da crise internacional. In: DAVI, J (Org). Seguridade social e saúde: tendências e desafios. Campina Grande: ADUEPB, 2009.

SOARES, P. Crise empurra 88 mil para o subemprego. Folha.com, São Paulo, 8 mar. 2009 Disponível em: <http://www1.folha.uol.com.br/fsp/dinheiro/fio803200902.htm>. Acesso em: 8 mar. 2009.

STÉDILE, J. A. De poucos para poucos: nada justifica a alta concentração da riqueza. Revista Carta Capital, n.600, jun. 2010.

TEIXEIRA, F. J. S; OLIVEIRA, M. A. de. Neoliberalismo e reestruturação produtiva: as novas determinações do mundo do trabalho. São Paulo: Cortez, 1996. 